\title{
JOGO ANIMACARDS CAATINGUEIROS: CONHECENDO OS ANIMAIS VERTEBRADOS DA CAATINGA E ENTENDENDO SUA IMPORTÂNCIA
}

\author{
Jéssica Gouveia Lira ${ }^{1}$ \\ Elâine Maria dos Santos Ribeiro² \\ Regina Lúcia Félix de Aguiar Lima ${ }^{3}$
}

Resumo: A fauna da Caatinga possui animais que estão ameaçados por ações antrópicas como a caça e desmatamento. O emprego de estratégias de Educação Ambiental na escola pode contribuir para valorização e conservação da fauna. Nesse sentido, o objetivo deste trabalho foi desenvolver um jogo didático para abordagem da fauna de vertebrados da Caatinga. $O$ jogo Animacards Caatingueiros inclui o perfil de 20 espécies de animais vertebrados terrestres da Caatinga, levando em consideração a vulnerabilidade e atratividade dessas espécies. Animacards Caatingueiros é um recurso didático para uso em sala de aula que contribui para a construção da consciência ambiental sobre a importância de conservação desses animais.

Palavras-chave: Metodologias Ativas; Educação Ambiental; Aprendizagem; Semiárido; Fauna.

Abstract: The Caatinga fauna has animals that are threatened by human actions such as hunting and deforestation. The use of Environmental Education strategies in schools can contribute to the valorization and conservation of fauna. In this sense, the objective of this work was to develop a didactic game to approach the vertebrate fauna of the Caatinga. The game Animacards Caatingueiros includes the profile of 20 species of terrestrial vertebrate animals from the Caatinga, taking into account the vulnerability and attractiveness of these species. Animacards Caatingueiros is a didactic resource for use in the classroom that contributes to the construction of environmental awareness about the importance of conservation of these animals.

Keywords: Active Methodologies; Environmental Education; Learning; Semiarid; Fauna.

\footnotetext{
1 Universidade de Pernambuco. E-mail: jessica.gouveia@upe.br. http://lattes.cnpq.br/7663203322654216

2 Universidade de Pernambuco. E-mail: elaine.ribeiro@upe.br. http://lattes.cnpq.br/3304685448889789

3 Universidade de Pernambuco. E-mail: regina.aguiar@upe.br. http://lattes.cnpq.br/8549101690272163
} 


\section{Introdução}

O Brasil é um dos países com maior diversidade biológica do mundo, sendo bastante conhecido por suas florestas tropicais úmidas (LEAL et al. 2003). Por outro lado, o conhecimento sobre a biodiversidade da Caatinga, que é uma de suas florestas secas, encontra-se em processo de conhecimento pela comunidade científica e ainda é pouco divulgada (LEAL et al. 2003; SILVA et al. 2017). Apesar de sua biota ser pouco conhecida até agora, a Caatinga é mais diversa que qualquer outra floresta seca que esteja exposta às mesmas condições de clima e de solo e a sua diversidade de vertebrados chega próximo a 1.400 espécies, sendo 23\% delas endêmicas (GARDA et al. 2018; FREIRE; PACHECO, 2017; SILVA et al. 2017).

A Caatinga possui grande diversidade de espécies, tanto de animais vertebrados como de invertebrados, além de plantas, fungos e microrganismos em geral, e apresenta também densidade populacional alta para uma região semiárida (CORREIA et al. 2011). Essa população humana realiza as atividades ligadas à caça e ao desmatamento que tem levado muitas espécies de animais a entrarem para a lista vermelha da União Internacional para a Conservação da Natureza (IUCN) e para a Lista Nacional das Espécies da Fauna Brasileira Ameaçadas de Extinção do Ministério do Meio Ambiente (BRASIL, 2014).

Uma das formas de contribuir para a valorização e conservação da biodiversidade da Caatinga e diminuir a ameaça às espécies é o ensino e prática da Educação Ambiental nas escolas a partir da utilização de recursos didáticos baseados em metodologias ativas como, por exemplo, os jogos didáticos. A abordagem sobre os animais da Caatinga na forma de jogos é uma maneira interessante para conscientização a respeito da preservação dessas espécies, além de ser um forte instrumento pedagógico para melhorar o processo de aprendizagem, despertando o interesse dos alunos e revertendo a aversão e monotonia ocasionada muitas vezes pelos métodos tradicionais de ensino (VIVIANI et al. 2016).

A utilização de jogos tem sido uma grande aliada da educação ambiental nas escolas. A gamificação é uma metodologia ativa de ensino, que envolve o uso de jogos para resolver problemas e para engajar os participantes. Esses jogos podem ser analógicos, eletrônicos ou até mesmo dinâmicas simples (ALVES et al. 2014; FARDO, 2013). A utilização dessas ferramentas torna o aprendizado mais atrativo e motivador para os alunos, uma vez que jogos podem gerar competição e/ou trabalho em equipe, o que pode instigar os alunos para aprender sobre os assuntos abordados em aula (ALVES et al. 2014). Além de ser uma metodologia mais atraente para os alunos, o uso de jogos serve como o feedback rápido para o professor de como a turma construiu conhecimentos sobre o assunto apresentado na aula (FARDO, 2013). Além disso, faz com que a sensibilização do aluno diante das questões ambientais ocorra de maneira prazerosa, permitindo que ocorra seu envolvimento integral, tanto racionalmente quanto emocionalmente. (GUIMARÃES, 2003). 
O objetivo deste trabalho foi desenvolver um jogo didático que sirva como instrumento de Educação Ambiental para abordagem dinâmica e lúdica dos vertebrados da Caatinga, suas características e importância de conservação. O jogo proposto contribui para avanços no $15^{\circ}$ Objetivo do Desenvolvimento Sustentável da Agenda 2030, que é "Proteger, recuperar e promover o uso sustentável dos ecossistemas terrestres, gerir de forma sustentável as florestas, combater a desertificação, deter e reverter a degradação da terra e deter a perda de biodiversidade".

\section{O jogo didático como ferramenta na Educação Ambiental para o conhecimento dos vertebrados da Caatinga}

A Biologia é a ciência que estuda a vida ou, mais precisamente, as características dos seres vivos (LINHARES; GEWANDSZNAJDER, 2010). Por ser uma ciência bastante complexa, a Biologia se divide em diversas áreas, dentre elas a Zoologia, que é o estudo dos animais ou da fauna. De acordo com os PCN's (Parâmetros Curriculares Nacionais), o ensino da Biologia deve levar ao entendimento da forma como os seres humanos se relacionam com a natureza e as mudanças que eles promovem na mesma (BRASIL, 2002). Assim, o estudo da Zoologia levará a compreensão dos animais e conhecimentos relacionados à conservação dos mesmos a fim de construir um ambiente sustentável, equilibrado e saudável (AZEVEDO et al. 2016).

A Caatinga contém uma diversidade de vertebrados considerada alta em comparação com outras florestas secas da Terra (GARDA et al. 2018; LEAL et al. 2003; SILVA et al. 2017). Há registro de 1406 espécies de vertebrados nesse ecossistema, considerando o somatório das espécies de peixes (386), anfíbios (98), répteis (191), aves (548) e mamíferos (183). Dentre os vertebrados terrestres, a maioria das espécies descritas são aves, a quantidade de espécies de mamíferos e répteis é semelhante, e os anfíbios têm menor quantidade de espécies descritas. O conhecimento sobre a fauna de vertebrados da Caatinga tem aumentado nas últimas duas décadas, e os especialistas consideram que há ainda muitas espécies a serem descritas (GARDA et al. 2018; SILVA et al. 2017).

As condições ambientais prevalentes na Caatinga são consideradas fatores que limitam a ocorrência e distribuição de espécies de anfíbios e répteis, grupos com espécies mais dependentes de áreas úmidas para viver (GARDA et al. 2018; SILVA et al. 2017). Assim, desmatamento e degradação ambiental são ações que agravam a manutenção dessas espécies no ecossistema. Aves e mamíferos, além de serem afetados pelo desmatamento e degradação, também são objeto da atividade de caça tradicional na região. Todos esses fatores, aliados à baixa extensão em área de proteção ambiental e efeitos das mudanças climáticas, reforçam a importância da necessidade de proteção para a fauna da Caatinga e tornam sua conservação um grande desafio (GARDA et al. 2018; SILVA et al. 2017; TABARELLI et al. 2018).

Para a solução desse desafio, além das contribuições dos cientistas, do poder público, da sociedade civil, a Educação Ambiental deve ser utilizada 
como ferramenta chave pois leva os indivíduos a refletir e o desenvolver consciência quanto à importância da conservação e biodiversidade, além de estimular a percepção das interferências negativas que o homem tem causado no meio ambiente (NORMAN; SEVERIANO, 2018). A reforma curricular prevista nos Parâmetros Curriculares Nacionais estabelece a Educação Ambiental como um tema transversal que preza pela interdisciplinaridade (BREDA; PICANÇO, 2011).

A utilização de jogos como instrumentos para a prática de Educação Ambiental pode auxiliar a sanar dúvidas deixadas pelo processo tradicional de ensino, além de colocar o aluno como protagonista no processo de aprendizagem. Além disso, o jogo didático incentiva o trabalho em grupo, contribui no processo de socialização, estimula a criatividade e a motivação (JÖTTEN; CAMARA, 2017).

O estudo realizado por Barros et al. (2018) mostrou que a utilização de jogos foi muito eficiente no aprendizado sobre as espécies de animais presentes no Parque Ecológico de Americana (SP) e na promoção do desenvolvimento da consciência ambiental. Este trabalho apresenta um jogo didático baseado no jogo de cartas Super Trunfo® o qual é disponibilizado aos visitantes do parque. Após a aplicação do recurso didático, os autores observaram a eficácia do método como ferramenta no ensino sobre os animais no zoológico e perceberam 0 envolvimento $e$ interesse dos participantes/jogadores, aprendendo de maneira divertida e estimulando 0 sentido investigativo e reflexivo.

Presti et al. (2017) elaboraram e aplicaram um jogo de tabuleiro com informações lúdicas sobre os riscos de extinção e propostas de conservação da arara-azul-grande, para alunos do Ensino Fundamental I e II de escolas na região do Mosaico de Carajás, no Pará. Os referidos autores verificaram boa aceitação e interesse das crianças e adolescentes, que participaram de maneira ativa do jogo e das discussões. Além disso, o recurso didático proporcionou melhor compreensão do conteúdo e despertou a curiosidade dos alunos, sendo possível concluir que estratégias lúdicas divertidas são eficientes na Educação Ambiental.

O jogo "Reconquista da Mata Ciliar", elaborado por Menezes et al. (2016), foi aplicado em turmas do $3^{\circ}$ ano do Ensino Médio de uma unidade de ensino da rede pública estadual do município de Itapetinga, no estado da Bahia, com objetivo de prestar esclarecimentos sobre as potencialidades e problemas enfrentados pela mata ciliar do Rio Catolé na zona urbana de Itapetinga. A partir dos resultados obtidos, foi possível perceber que as ferramentas utilizadas contribuíram para o processo de aprendizagem, sendo eficiente na construção do conhecimento científico de maneira lúdica e divertida. Além disso, os autores destacam a importância do ambiente escolar para a Educação Ambiental, pois proporciona aos alunos senso crítico, sensibilizando-os quanto às questões de conservação e preservação do meio ambiente. 
O jogo de tabuleiro Perfil®, que serviu como base para a construção do recurso didático proposto neste trabalho, também foi utilizado no desenvolvimento do jogo "Perfil Químico: um jogo para o ensino da tabela periódica" (ROMANO et al. 2017), que foi feito visando ensinar a tabela periódica de forma enérgica e didática. $O$ jogo foi aplicado em turmas do ensino Médio de uma escola pública em Bauru, São Paulo. Após aplicação do jogo, uma avaliação com uso de questionário mostrou que $55 \%$ dos alunos declararam ter tido maior facilidade na compreensão do conteúdo com o uso do jogo e que $92 \%$ dos alunos gostariam que mais conteúdos fossem trabalhados por meio de jogos. Os autores concluíram que a aprendizagem foi mais significativa, uma vez que as cartas proporcionaram debates e discussão dos conceitos, facilitando a compreensão do assunto proposto.

\section{Metodologia}

O jogo Animacards Caatingueiros foi baseado no jogo Perfilß, que é distribuído no Brasil pela Grow Jogos e Brinquedos Ltda.® com cartas, contendo dicas sobre temas diversos, como pessoas, anos, coisas ou lugares, no qual os jogadores deverão descobrir de quem é o perfil em questão. É um jogo juvenil/adulto, indicado a partir de 12 anos de idade.

Inicialmente, foi realizada a seleção das espécies de vertebrados para serem incluídos no jogo. Os vertebrados foram selecionados, levando em consideração sua vulnerabilidade (IUCN, 2001, 2012) e atratividade, os animais carismáticos podem servir como espécies bandeiras, permitindo que sejam conhecidos pela população, sensibilizando e conscientizando a sociedade sobre a necessidade de conservação dessas espécies. Foram selecionadas 20 espécies de animais vertebrados encontrados na Caatinga. Nessa lista, estão incluídas espécies de anfíbios, répteis, aves e mamíferos.

As informações para criar as dicas presentes nas cartas de cada espécie foram obtidas nos sites Toda Matéria, WikiAves, National Geographic e Ministério do Meio Ambiente. As fotos utilizadas são dos sites Toda Matéria, WikiAves, BioFaces e Wikipédia.

As espécies selecionadas foram classificadas quanto ao grau do risco de extinção das espécies. Para isso foram utilizadas as categorias de acordo com a avaliação global da União Internacional para a Conservação da Natureza (UICN), utilizada no Livro Vermelho da Fauna Brasileira Ameaçada de Extinção (ICMBIO, 2018), divulgado pelo Instituto Chico Mendes de Conservação da Biodiversidade (ICMBio).

As categorias de risco estabelecidas pela UICN são agrupadas em 3 conjuntos, sendo que o grupo com risco mais brando é composto pelas categorias LC (Least Concern) e NT (Near Threatened); o grupo com risco real para as espécies ameaçadas é formado pelas categorias VU (Vulnerable), EN (Endangered) e CR (Critically Endangered). O grupo com espécies em situação mais grave, ou seja, que contêm espécies de animais extintos ou provavelmente extintos, é constituído pelas categorias EW (Extinct in the Wild) e EX (Extinct) (ICMBIO, 2018).

revista brasileira educação ambiental 
Segundo a IUCN $(2001,2012)$, a categoria de risco LC significa que a espécie está classificada como segura ou pouco preocupante. A categoria NT significa que a espécie está classificada como quase ameaçada, ou seja, está perto de ser classificada ou provavelmente será incluída em uma das categorias de ameaça (VU, EN ou CR) (IUCN, 2001, 2012).

A categoria de risco VU quer dizer vulnerável, o que significa que a espécie está enfrentando um risco alto de extinção na natureza (IUCN, 2001, 2012). A categoria $E N$ quer dizer que a espécie se encontra em perigo, com risco muito alto de extinção (IUCN, 2001, 2012). Já a categoria CR significa que o animal se encontra criticamente em perigo e é utilizado para espécies que estão enfrentando um risco extremamente alto de extinção na natureza (IUCN, 2001, 2012).

Por fim, as categorias de risco EW e EX são utilizadas para espécies já extintas (ICMBIO, 2018; IUCN, 2001, 2012). A categoria EW é empregada para espécies já extintas na natureza, quando sua sobrevivência é conhecida apenas em cultivo, cativeiro ou como uma população (ou populações) naturalizada fora da sua área de distribuição natural. Quando não há qualquer dúvida razoável que o último indivíduo morreu, a espécie é considerada extinta (EX). Quando há evidências de que a espécie foi extinta, mas, no entanto, ainda não ocorreram buscas satisfatórias para afirmar que o último indivíduo tenha morrido, por cautela, a espécie é classificada como $\mathrm{CR}$, mas com uma indicação de possivelmente extinta, ficando a notação como $\mathrm{CR}(\mathrm{PEX})$. Caso a espécie em questão possua população em cativeiro, a notação é CR(PEW), do inglês "possibly extinct in the wild", que significa possivelmente extinta na natureza (ICMBIO, 2018).

O jogo de tabuleiro apresentado neste trabalho faz parte da proposta "Aprendendo sobre o valor da biodiversidade da Caatinga e seus serviços ecossistêmicos no ensino escolar" apoiada pela Fundação de Amparo à Ciência e Tecnologia do Estado de Pernambuco (APQ - 0177-2.05/18). Pretende-se que esse recurso didático sirva como instrumento para valorização e aprendizagem sobre os vertebrados da Caatinga no ensino básico, no entanto, não foi possível sua aplicação nas escolas para atestar a sua efetividade devido a pandemia causada pela COVID-19.

\section{Resultados e discussão}

Foram selecionadas 20 espécies de animais vertebrados terrestres que ocorrem na Caatinga para inclusão no Animacards Caatingueiros, que estão distribuídas nas classes anfíbios, répteis, aves e mamíferos (Tabela 1).

Há predomínio de espécies de mamíferos e de aves na lista e isso tem relação com o conhecimento da biodiversidade da Caatinga, que é maior e mais antigo sobre esses grupos. O conhecimento sobre a fauna de anfíbios e répteis ainda precisa avançar bastante (ALBUQUERQUE, 2012; TABARELLI et al. 2018). 
Tabela 1: Nomes das espécies, das classes e o grau de risco de extinção de vertebrados terrestres da Caatinga incluídas no jogo Animacards Caatingueiros.

\begin{tabular}{|c|c|c|c|}
\hline Nome popular & Nome científico (Autor, ano) & Classe & $\begin{array}{l}\text { Risco de } \\
\text { Extinção }\end{array}$ \\
\hline Águia-chilena & Geranoaetus melanoleucus (Vieillot, 1819) & Ave & LC \\
\hline Arara-azul-de-lear & Anodorhynchus leari (Bonaparte, 1856) & Ave & EN \\
\hline Ararinha-azul & Cyanopsitta spixii (Wagler, 1832) & Ave & CR - PEW \\
\hline Asa-branca & Patagioenas picazuro (Temminck, 1813) & Ave & LC \\
\hline Cachorro-do-mato & Cerdocyon thous (Linnaeus, 1766) & Mamífero & LC \\
\hline Calango-de-cauda-verde & $\begin{array}{l}\text { Ameivula venetacaudus } \\
\text { (Harvey et al. 2012) }\end{array}$ & Réptil & EN \\
\hline Carcará & Caracara plancus (Miller, 1777) & Ave & LC \\
\hline Corrupião & Icterus jamacaii (Gmelin, 1788) & Ave & LC \\
\hline Cutia & Dasyprocta prymnolopha (Wagler, 1831) & Mamífero & LC \\
\hline Gambá-de-orelha-branca & Didelphis albiventris (Lund, 1840) & Mamífero & LC \\
\hline Gato-maracajá & Leopardus wiedii (Schinz, 1821) & Mamífero & VU \\
\hline Jaó-do-sul & Crypturellus noctivagus (Wied, 1820) & Ave & NT \\
\hline Jiboia & Boa constrictor (Linnaeus, 1758) & Réptil & LC \\
\hline Macaco-prego & Sapajus libidinosus (Spix, 1823) & Mamífero & NT \\
\hline Mocó & Kerodon rupestris (Wied-Neuwied, 1820) & Mamífero & VU \\
\hline Onça-parda & Puma concolor (Linnaeus, 1771) & Mamífero & VU \\
\hline Perereca-de-capacete & Corythomantis greeningi (Boulenger, 1896) & Anfíbio & LC \\
\hline Queixada & Tayassu pecari (Link, 1795) & Mamífero & VU \\
\hline Sagui-de-tufo-branco & Callithrix jacchus (Linnaeus, 1758) & Mamífero & LC \\
\hline Tatu-bola & Tolypeutes tricinctus (Linnaeus, 1758) & Mamífero & EN \\
\hline
\end{tabular}

Fonte: Autoria própria. Categorias de risco de extinção: LC (Least Concern/ Pouco Preocupante), NT (Near Threatened/ Quase Ameaçada), VU (Vulnerable/ Vulnerável), EN (Endangered/ Em Perigo) e CR - PEW (Critically Endangered/Criticamente em Perigo - Possibly Extinct in the Wild/Possivelmente Extinta na Natureza) (IUCN, 2001, 2012).

As espécies selecionadas apresentaram variação no grau do risco de extinção (BRASIL, 2014; ICMBIO, 2018). Na lista, há 10 espécies de animais enquadrados na categoria de risco Menos Preocupante (LC). São elas: Águiachilena (Geranoaetus melanoleucus), Asa-branca (Patagioenas picazuro), Cachorro-do-mato (Cerdocyon thous), Carcará (Caracara plancus), Corrupião (Icterus jamacail), Cutia (Dasyprocta prymnolopha), Gambá-de-orelha-branca

Revbea, São Paulo, V. 15, № 6: 99-118, 2020.

revista brasileira 
(Didelphis albiventris), Jiboia (Boa constrictor), Perereca-de-capacete (Corythomantis greeningi) e Sagui-de-tufo-branco (Callithrix jacchus).

$\mathrm{Na}$ categoria de risco Quase Ameaçado (NT), estão 2 espécies, Jaódo-sul (Crypturellus noctivagus) e Macaco-prego (Sapajus libidinosus) (BRASIL, 2014; ICMBIO, 2018).

Animais nas categorias VU (vulnerável), EN (em perigo) e CR (em perigo crítico) estão sob ameaça de extinção real. Dentre os animais incluídos no Animacarda Caatingueiros, há 4 espécies classificadas como vulneráveis (VU), pois enfrentam risco alto de extinção na natureza. São elas: Gatomaracajá (Leopardus wiedii), Mocó (Kerodon rupestris), Onça-parda (Puma concolor) e Queixada (Tayassu pecarı).

$\mathrm{Na}$ categoria Em Perigo (EM), em situação de risco muito alto de extinção na natureza, há 2 espécies de animais, o Calango-de-cauda-verde (Ameivula venetacaudus) e o Tatu-bola (Tolypeutes tricinctus) (BRASIL, 2014; ICMBIO, 2018).

A categoria CR quer dizer Criticamente em Perigo e é utilizada para espécies que estão enfrentando um risco extremamente alto de extinção na natureza (IUCN, 2001, 2012). Dentre os animais listados, somente a Ararinhaazul se enquadra nessa categoria, pois há sinais de que a espécie foi extinta na natureza, sem haver, no entanto, confirmação de que seu último representante na natureza tenha morrido (BRASIL, 2014; ICMBIO, 2018). Como para essa espécie há população em cativeiro, com possibilidade de reprodução e reinserção na natureza, a notação CR tem acréscimo da sigla PEW (Possibly Extinct in the Wild/ Possivelmente Extinta na Natureza) (IUCN, 2001, 2012).

\section{Descrição do jogo Animacards Caatingueiros}

As cartas do jogo Animacards Caatingueiros têm dimensões de $6 \mathrm{~cm}$ de largura e $9 \mathrm{~cm}$ de altura, conforme o modelo (Figura 1). As cartas possuem na frente a foto do animal, o nome popular, o nome científico e cinco informações variadas (dicas e/ou curiosidades) sobre o vertebrado e, no verso, uma paisagem da Caatinga.

Animacards Caatingueiros é constituído por um conjunto de 20 cartas (Figura 2), 1 tabuleiro de $24 \mathrm{~cm}$ de largura e $16 \mathrm{~cm}$ de altura (Figura 3), manual de instruções (Figura 4), 5 fichas na forma de círculo, 2 dados e 5 peões.

As fichas, os dados e os peões podem ser confeccionados pelos professores e alunos ou podem ser adquiridos materiais diversos para esse fim. Além disso, os peões podem ser animais da Caatinga.

A aplicação do jogo pelo professor deverá ser realizada após o tema Biodiversidade da Caatinga ter sido abordado em sala de aula, especificamente os animais vertebrados terrestres. O professor pode solicitar aos alunos que realizem pesquisa sobre o tema também. Além disso, o professor poderá 
indicar referências para estudo prévio sobre o tema para discussão e preparação para atividade em grupo (jogo).

A dinâmica desse jogo de tabuleiro estabelece que o início seja definido jogando dados; o jogador que somar mais pontos inicia a rodada. $O$ jogador que inicia o jogo, é o mediador da rodada, deve retirar uma carta e informar as dicas solicitadas pelos demais integrantes da partida, os quais tentam adivinhar qual animal vertebrado da Caatinga está com o perfil descrito na carta.

Ao acertar as dicas sobre os animais contidas nas cartas, o jogador deve avançar o número de casas equivalente ao número correspondente nos dados, somando a pontuação extra a cada dica não revelada. Vence o jogador que chegar primeiro ao final do caminho.
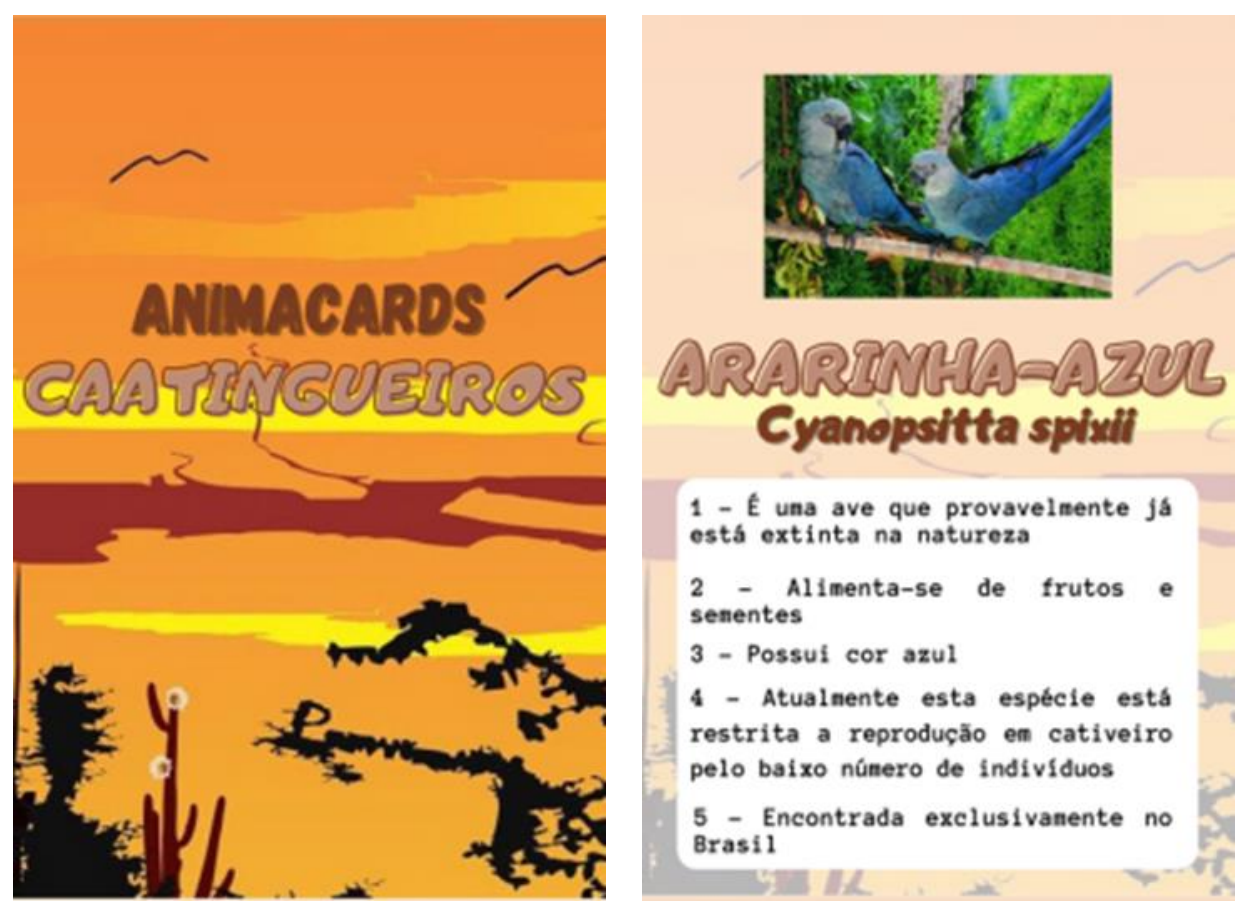

Figura 1: Modelo das cartas do jogo Animacards Caatingueiros em tamanho real, verso e frente de uma carta

Fonte: Autoria própria. 


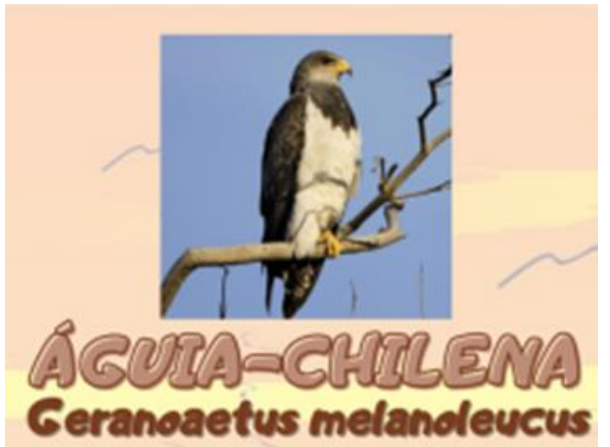

1 - E una ave preta e branca

2 - En voo con asas abertas, pode chegar a 2 n de envergadura

3 - Costuna fazer voos planos en busca de conida

4 - Pode chegar até cerca de $68 \mathrm{~cm}$ de comprinento

5 - Eventualmente, possui hábitos saprofagos

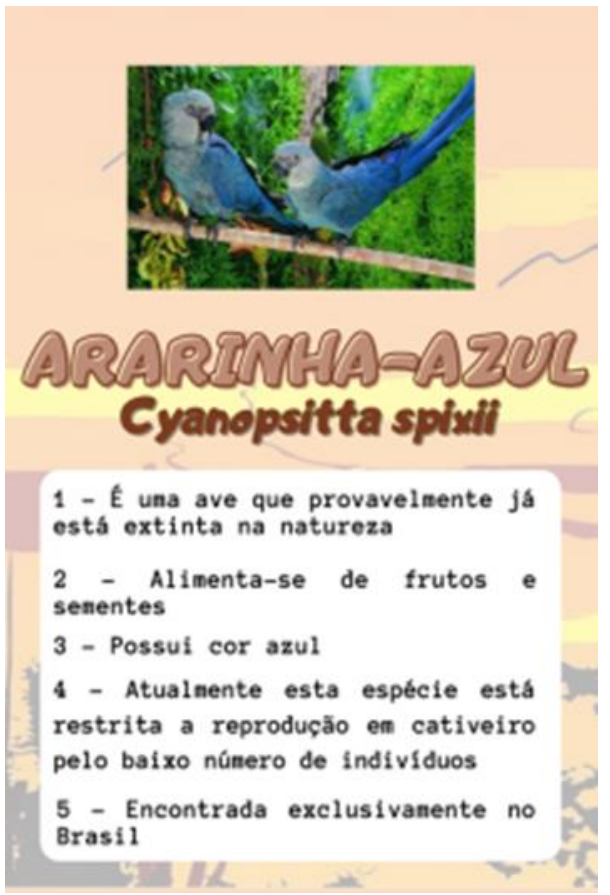

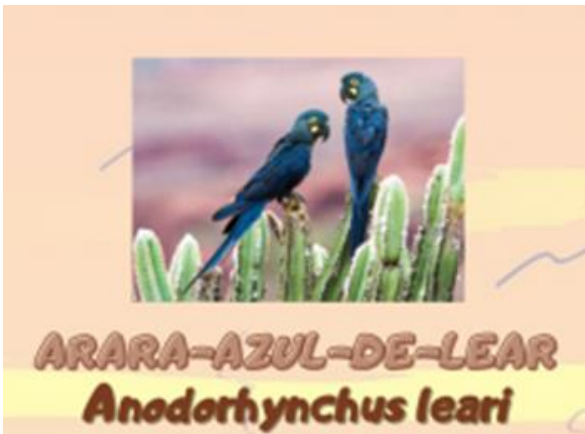

1 - Criticamente ameaçada, é uma das aves nais raras do nundo

2 - 0 tráfico de aninais silvestres e a destruiçăo do habitat săo os principais fatores de aneaça à espécie

3 - Muitas vezes 6 confundida com a arara-azul

4 - Vive nuna regiăo extrenanente restrita do sertăo baiano

5 - Alimenta-se basicanente de cocos da palmeira Licuri (Syagrus coronata)

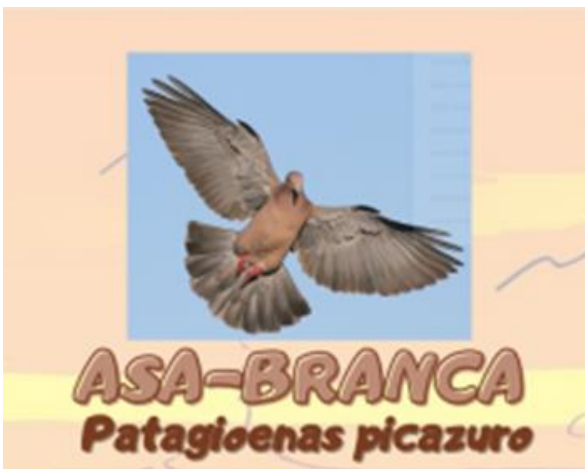

1 - E conhecida cono "pombão"

2 - E una ave nigratória, voa grandes distâncias

3 - Fol Inspiraçăo para una cançăo nuito fanosa de Luiz Gonzaga

4 - Mede cerca de $34 \mathrm{~cm}$

5 - Possuí una listra branca on suas asas

Figura 2: Cartas do jogo Animacards Caatingueiros, em tamanho real Fonte: Autoria própria. 

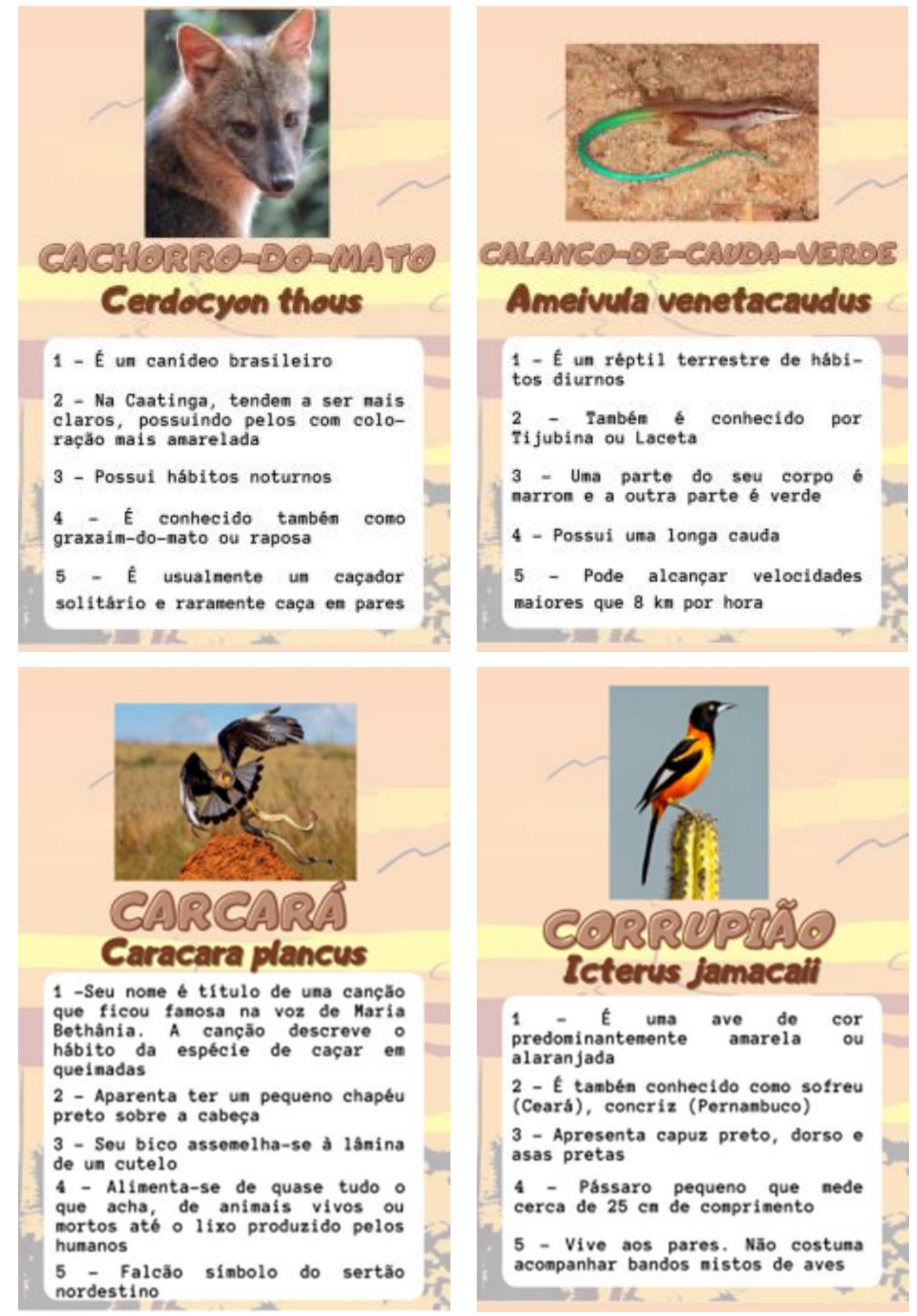

Figura 2: Cartas do jogo Animacards Caatingueiros, em tamanho real (Continuação).

Fonte: Autoria própria. 


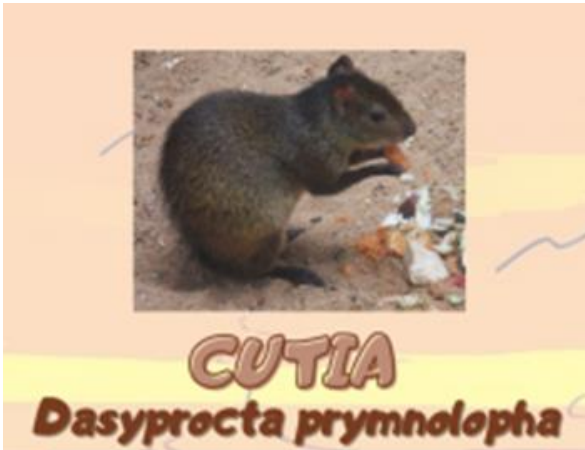

1 - E un manífero roedor endênico do nordeste do brasileiro

2 - Alimenta-se de vegetais, cereais, tubérculos e frutas

3 - Apresenta inportante papel na dispersăo de sementes, una vez que possui o hábito de enterrar seu alimento

4 - Pesan, en média, de $3 \mathrm{~kg}$ a $6 \mathrm{~kg}$

5 - E un roedor de pequeno porte, medindo entre 49 e 64 centínetros

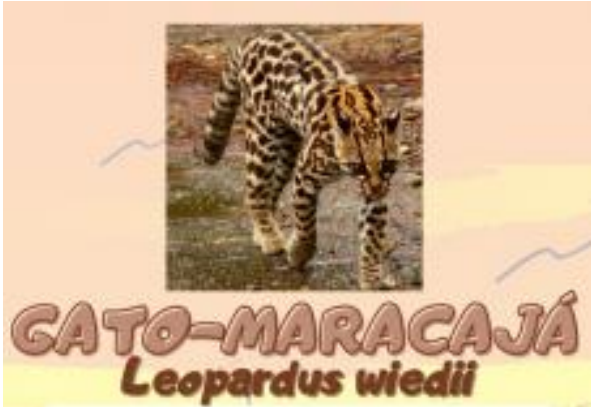

1 - Na Caatinga, sua distribuição e mais restrita a areas de transiçăo vegetacional e cânions de mata densa

2 - A espécie está enfrentando um rísco alto de extinçăo na natureza

3 - Sofre bastante deviđo a açōes antrópicas como a caça e o desmatanento

4 - Possui grande capacidade de salto e pode caminhar nas pontas dos galhos dos arbustos

5 - Seus hábitos săo noturnos e alimenta-se de pequenos roedores

e aves, que caça nas arvores.

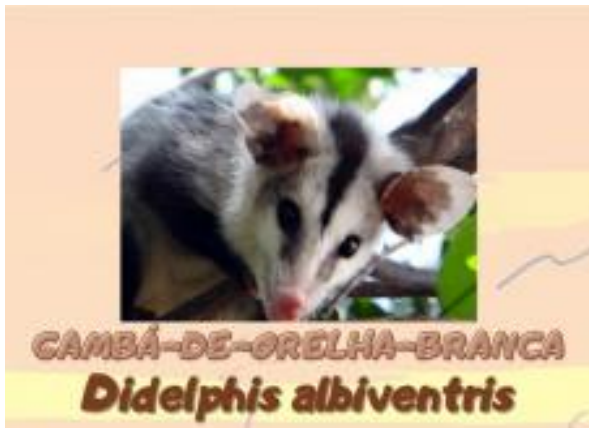

1 - A sua pelagen é pretaacizentada no corpo, preta no rabo e branca nas orelhas e no rosto

2 - Possui una listra preta na cabeça e manchas pretas ao redor dos olhos

3 - Tambén é conhecido cono Tinbu 4 - $E$ un aninal de hábitos norturnos

5 - Alimenta-se de invertebrados, pássaros, pequenos maniferos, cobras, lagartos, anfibios, frutas.

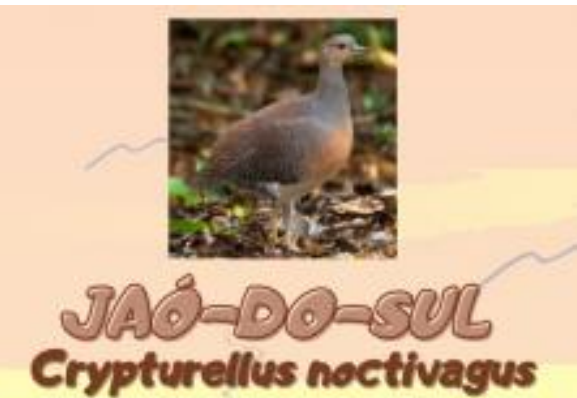

1 - Tambén é chamado de zebelê e zanbelê

2 - Alimenta-se principalnente de pequenos frutos de palmeiras, mas pode coner pequenos invertebrados e algunas espêcies de gramineas 3 - Mede entre 32 a 37 centinetros 4 - Seu piado é ressoante e pode ser ouvido a distancía, e no período da reprodução piam inclusive noite adentro.

5 - 0 desnatamento, caça $\theta$ a ocupaçăo inobiliária de suas areas de ocorrência natural têm contribuido para ameaçá-1o

Figura 2: Cartas do jogo Animacards Caatingueiros, em tamanho real (Continuação). Fonte: Autoria própria. 

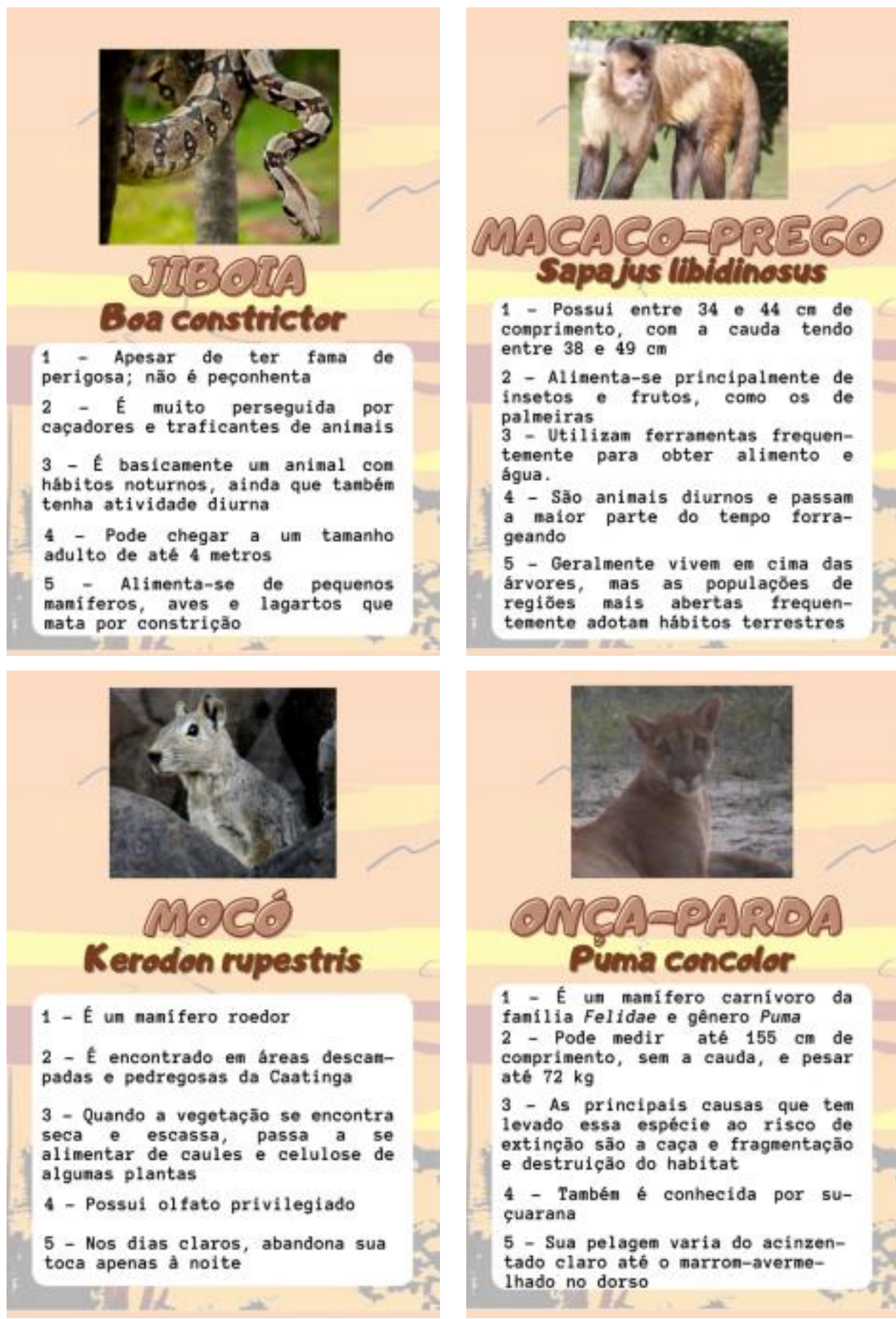

1 - Possui entre 34 e 44 cn de comprimento, con a cauda tendo entre 38 e $49 \mathrm{~cm}$

2 - Alimenta-se principalmente de insetos e frutos, como os de palmeiras

3 - Utilizam ferranentas frequentemente para obter alimento $e$ água.

4 - Săo aninais diurnos e passam a maior parte do tenpo forrageando

5 - Geralmente viven en cima das arvores, mas as populaçōes de regioles mais abertas frequentemente adotan hábitos terrestres

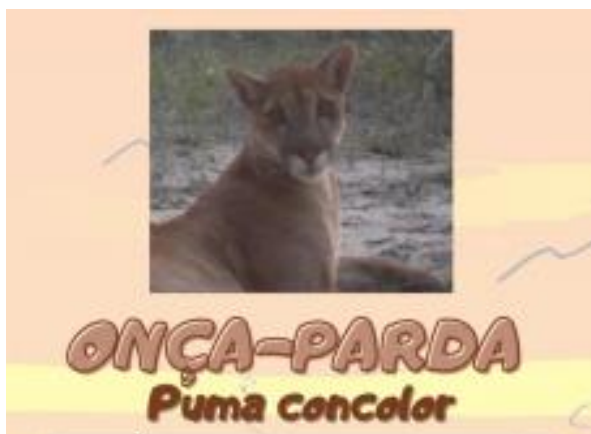

1 - É un manifero carnivoro da fanilia Felidae e gênero Puma 2 - Pode medir até $155 \mathrm{~cm}$ de conprimento, sen a cauda, e pesar até $72 \mathrm{~kg}$

3 - As principais causas que ten levado essa espécie ao rísco de extinçāo são a caça e fragmentação e destruiçăo do habitat

4 - Tambén é conhecida por suçuarana

5 - Sua pelagem varia do acinzentado claro até o marron-averme-

Ihado no dorso

hado no dorso

Figura 2: Cartas do jogo Animacards Caatingueiros, em tamanho real (Continuação). Fonte: Autoria própria. 


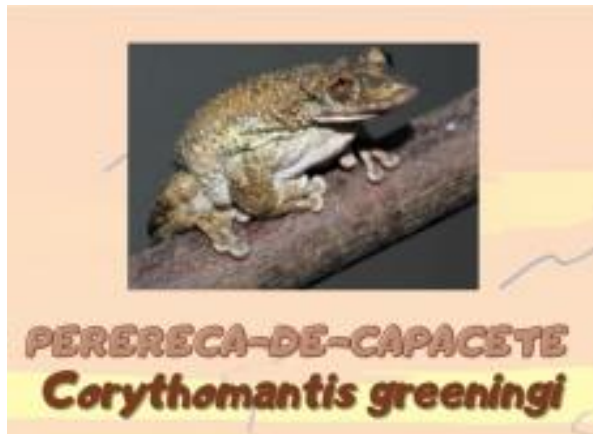

1 - É um anfíbio

2 - Seu none é devido ao formato de sua cabeça, que é coossificado

3 - Alén ser venenosa, ten o poder de injetar o veneno na vitima através de estruturas em formato de espinhas

4 - Possui cerca de 8 cn de comprimento

5 - Viven sobre folhas, bronélias, buracos de arvores e fendas de rochas

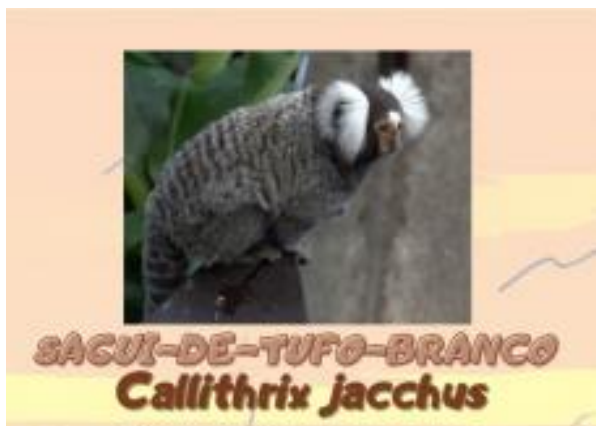

1 - É una espécie de nacaco de pequeno porte

2 - Seus pelos são mesclados en

cinza e branco, sendo que nas

orelhas a cor branca

3 - Sua cauda é maior do que o corpo e ten a função de garantir seu equilibrio

4 - Habita florestas arbustivas da caatinga e a mata atlântica do Nordeste brasileiro

5 - Alinentan-se de insetos, aranhas, pequenos vertebrados. ovos e pássaro, frutos e săo

tanbém gunívoros
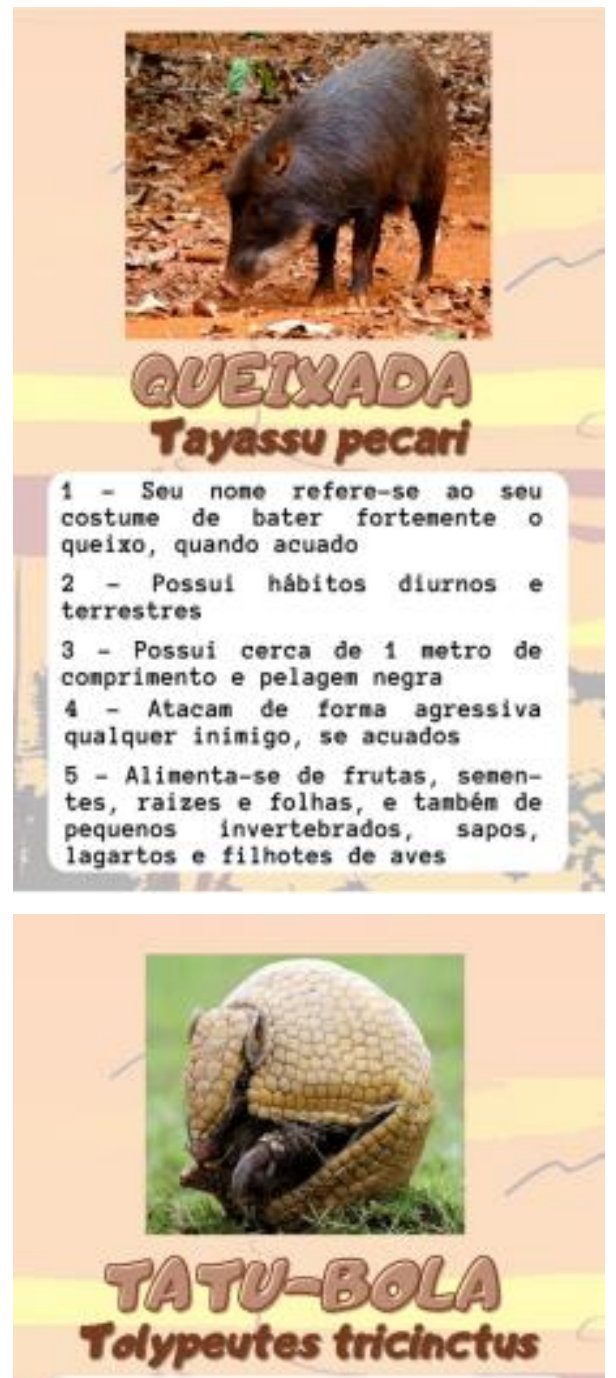

1 - Possui carapaça rígida

2 - Quando en perigo, fica em forma de bola

3 - Foi escolhido como mascote da Copa do Mundo de 2014

4 - Se alimenta de cupin

5 - Seu peso pode chegar até $1,8 \mathrm{~kg}$

Figura 2: Cartas do jogo Animacards Caatingueiros, em tamanho real (Continuação). Fonte: Autoria própria. 


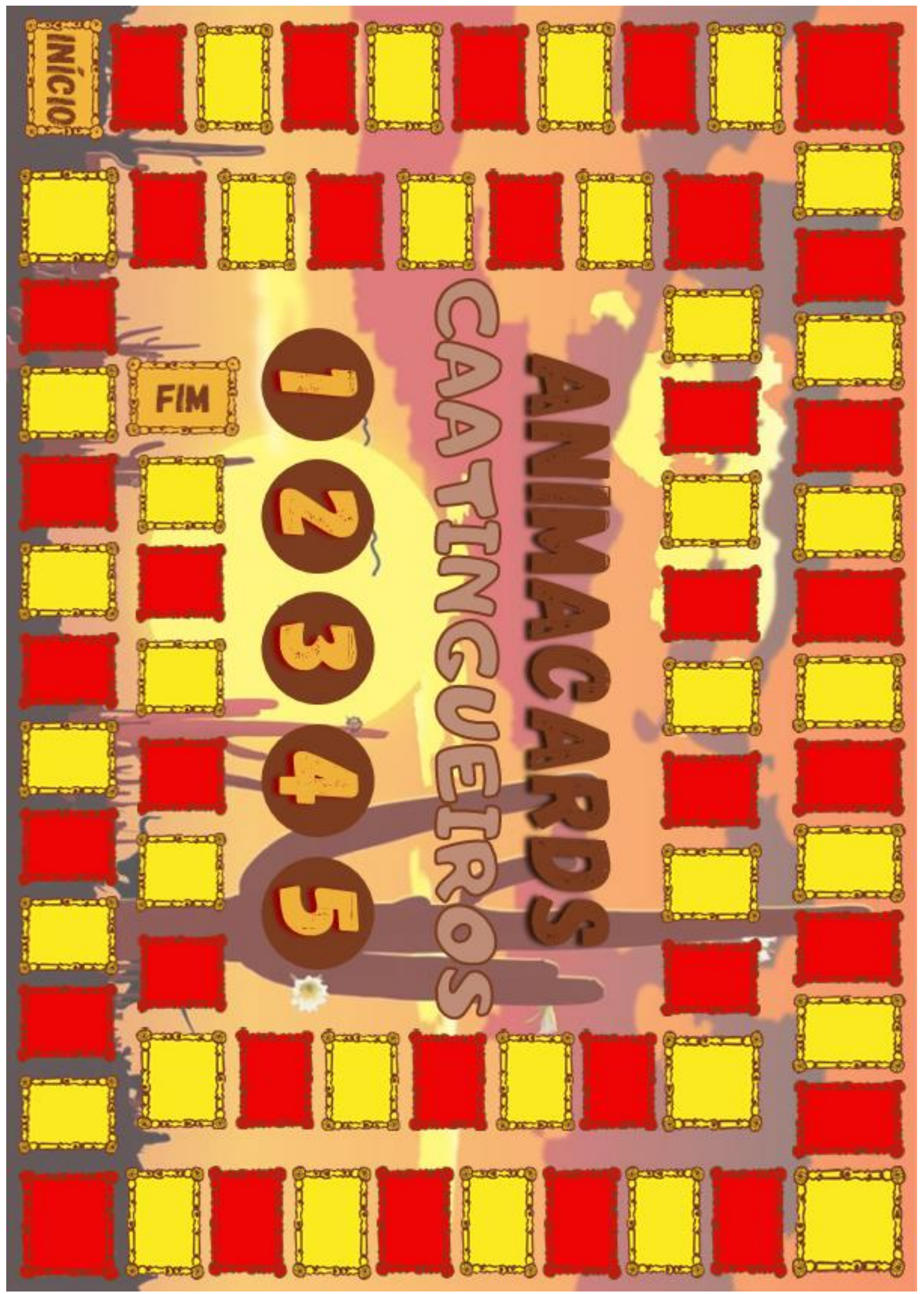

Figura 3: Tabuleiro do jogo Animacards Caatingueiros.

Fonte: Autoria própria.

Revbea, São Paulo, V. 15, № 6: 99-118, 2020.

revista brasileira

educação ambiental 


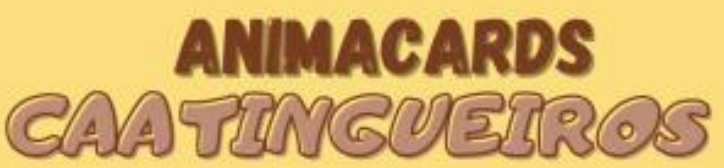

MANUAL DE INTRUÇÖES

COMO JOGAR?

1 - Devem participar do jogo 2 a 5 jogadores.

2 - Os jogadores devem jogar os dados e aquele que somar maior número de pontos passa a ser o mediador da primeira rodada e deve pegar a primeira carta da pilha.

3 - O jogador à esquerda do mediador deve lançar os dados e somar o valor correspondente aos dois dados lançados.

4 - Feito isso, o jogador escolhe um número de 1 a 5 e, em seguida, coloca uma ficha vermelha sobre a casa do tabuleiro de mesmo número.

5 - O mediador lê em voz alta a dica com o número escolhido pelo jogador.

6 - Depois da leitura da dica, o jogador que a escolheu pode dar um palpite sobre o animal vertebrado da Caatinga da carta ou pedir mais uma dica.

7 - Se o jogador acertar o palpite, ele receberá um ponto para cada dica não revelada (o que será igual ao número de fichas vermelhas fora do tabuleiro), esses pontos são somados ao valor correspondente ao lançamento dos dados realizado anteriormente pelo jogador. O jogador deve avançar seu peão no tabuleiro o número de casas igual ao número de pontos recebidos.

Exemplo: Se o jogador somou 8 pontos no lançamento dos dados e acertou o palpite após a segunda dica, ele avançará seu peão 11 espaços.

8 - Se errar, a vez de jogar passa para o próximo jogador á esquerda, que fará o mesmo que o anterior: lançará os dados novamente e escolherá um número de 1 a 5 (dentre os que ainda não foram escolhidos. Deverá colocar na respectiva casa numerada outra ficha vermelha, receberá a dica, dará um palpite e assim por diante. Não há penalidade para o jogador que errar o palpite.

9 - Em rodadas com apenas 2 jogadores, devem ser puxadas novas cartas a cada troca de mediador.

10 - Vence o jogador que chegar com seu peão ao final da trilha do tabuleiro primeiro (não é necessário chegar lá com o número exato).

\section{JOGO EM EQUIPE}

O jogo "Animacards Caatingueiros" pode ser jogado em equipe, facilitando sua aplicação na sala de aula. Para isso, a equipe deve participar utilizando um único peão e agindo como se fosse um único jogador. Cada equipe deve ter um lider que será responsável em ler as dicas quando for atuar como mediadora. Os integrantes podem debater entre si, no entanto, para evitar confusöes, devem deixar que seu lider fale em nome da equipe.

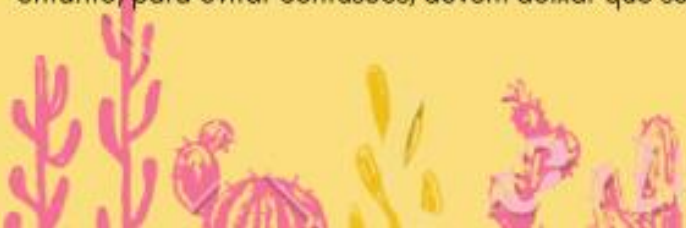

Figura 4: Manual de instruções contendo regras do jogo Animacards Caatingueiros.

Fonte: Autoria própria. 


\section{Regras e dinâmica do jogo Animacards Caatingueiros}

1. Devem participar do jogo 2 a 5 jogadores.

2. Os jogadores devem jogar os dados e aquele que somar maior número de pontos passa a ser o mediador da primeira rodada e deve pegar a primeira carta da pilha.

3. O jogador à esquerda do mediador deve lançar os dados e somar o valor correspondente aos dois dados lançados.

4. Feito isso, o jogador escolhe um número de 1 a $5 \mathrm{e}$, em seguida, coloca uma ficha vermelha sobre a casa do tabuleiro de mesmo número. jogador.

5. O mediador lê em voz alta a dica com o número escolhido pelo

6. Depois da leitura da dica, o jogador que a escolheu pode dar um palpite sobre o animal vertebrado da Caatinga da carta ou pedir mais uma dica.

7. Se o jogador acertar o palpite, ele receberá um ponto para cada dica não revelada (o que será igual ao número de fichas vermelhas fora do tabuleiro). Esses pontos são somados ao valor correspondente ao lançamento dos dados realizado anteriormente pelo jogador. $O$ jogador deve avançar seu peão no tabuleiro conforme o número de casas igual ao número de pontos recebidos. Exemplo: Se o jogador somou 8 pontos no lançamento dos dados e acertou o palpite após a segunda dica, ele avançará seu peão 11 espaços, pois soma-se os 8 pontos dos dados com 3 pontos de dicas não usadas para acertar o animal.

8. Se errar, a vez de jogar passa para o próximo jogador à esquerda, que fará o mesmo que o anterior: lançará os dados novamente e escolherá um número de 1 a 5 (dentre os que ainda não foram escolhidos). Deverá colocar na respectiva casa numerada outra ficha vermelha, receberá a dica, dará um palpite e assim por diante. Não há penalidade para o jogador que errar o palpite.

9. Em rodadas com apenas 2 jogadores, devem ser escolhidas novas cartas a cada troca de mediador.

10. Vence o jogador que chegar com seu peão ao final da trilha do tabuleiro primeiro; não é necessário chegar lá com o número exato, basta chegar na casa FIM do jogo.

\section{Variações para o Animacards Caatingueiros}

Além da forma e dinâmica propostas neste trabalho, os professores e alunos podem introduzir variações no jogo, tais como a realização de partidas em equipe e a ampliação das cartas.

O jogo em equipe pode ser uma estratégia para facilitar e viabilizar sua aplicação na sala de aula. Para isso, a participação da equipe deve ser feita 
utilizando um único peão e agindo como se fosse um único jogador. Nesse caso, cada equipe deve ter um líder, que será responsável em ler as dicas quando for atuar como mediadora. Os integrantes podem debater entre si; no entanto, para garantir a ordem no jogo, somente o líder deve falar em nome da equipe.

Professores e/ou alunos podem criar outras cartas e ampliar o jogo com outros animais da Caatinga. Além disso, podem fazer um jogo com temática exclusiva de peixes da Caatinga, contemplando assim outros grupos da fauna, como peixes e invertebrados. Também pode ser adaptado e utilizado para o conhecimento de espécies de plantas que compõem a flora.

O jogo Animacards Caatingueiros é uma proposta com potencial para contribuir efetivamente no fortalecimento do conhecimento dos vertebrados da Caatinga, podendo ter seu uso ampliado para o estudo da sua biodiversidade.

\section{Conclusões}

O jogo Animacards Caatingueiros é um instrumento didático baseado em metodologias ativas de aprendizado com aplicação prática na abordagem da Educação Ambiental nas escolas, especialmente para aquelas situadas na Caatinga. Ele serve de estímulo para o desenvolvimento da consciência ambiental, bem como contribui para o aprofundamento do conhecimento sobre vertebrados terrestres e sobre as espécies que ocorrem na Caatinga.

Animacards Caatingueiros propicia aos alunos a percepção do risco de extinção de espécies e da importância da proteção desses animais para a conservação da Caatinga, como também estimula nos alunos a reflexão de forma crítica sobre as interferências do homem no meio ambiente e suas consequências negativas para a biodiversidade.

\section{Agradecimentos}

Ao Programa de Pós-graduação em Ciência e Tecnologia Ambiental (PPGCTA) da Universidade de Pernambuco Campus Petrolina.

À Coordenação de Aperfeiçoamento de Pessoal de Nível Superior (CAPES), Brasil - Código de Financiamento 001.

À Fundação de Amparo a Ciência e Tecnologia do Estado de Pernambuco (FACEPE) pela concessão de bolsas e financiamento do projeto "Aprendendo sobre o valor da biodiversidade da Caatinga e seus serviços ecossistêmicos no ensino escolar" (FACEPE APQ - 0177-2.05/18). 


\section{Referências}

ALBUQUERQUE, U.P. et al. Caatinga revisited: ecology and conservation of an important seasonal dry forest. Scientific World Journal, v. 205182, p. 1-18, 2012.

ALVES, L.R.G.; MINHO, M.R.S.; DINIZ, M.V.C. Gamificação: diálogos com a educação. In: FADEL, L.M.; ULBRICHT, V.R.; BATISTA, C.R.; VANZIN,T. (org.). Gamificação na Educação. São Paulo: Editora Pimenta Café, 2014.

AZEVEDO, M.E.O.; OLIVEIRA, M.C.A.; LIMA D.C. A zoologia no ensino médio de escolas estaduais do município de Itapipoca, Ceará. Revista da SBEnBio, v. 3, n. 9, p. 6143-6154, 2016.

BARROS, J.D.; ORTOLANO, S.M.C.M.; FUJIHARA, R.T. Zoo Cards - o super trunfo animal: um jogo didático como ferramenta para o ensino no zoológico. Revista Brasileira de Educação Ambiental (RevBEA), v. 13, n. 4, p. 145-155, 2018.

BRASIL. Ministério da Educação. Parâmetros Curriculares Nacionais - Ensino médio. Orientações educacionais complementares aos Parâmetros Curriculares Nacionais. Ciências da Natureza, Matemática e suas Tecnologias, v. 32, 2002.

BRASIL. Ministério do Meio Ambiente. Portaria no 444 de 17 de dezembro de 2014. Lista Oficial das Espécies da Fauna Brasileira Ameaçadas de Extinção. 2014.

BREDA, T.V.; PICANÇO, J.L. A educação ambiental a partir de jogos: aprendendo de forma prazerosa e espontânea. In: Simpósio de Educação Ambiental e Transdisciplinaridade. 2, 2011, Goiânia. Anais [...]. Goiânia: UFG/IESA/NUPEAT, 2011.

CORREIA, R.C.; KILL, L.H.P.; MOURA, M.S.B.; CUNHA, T.J.F.; JESUS JÚNIOR, L.A.; ARAÚJO, J.L.P. A região semiárida Brasileira. In: VOLTOLINI, T.V. (Org.). Produção de caprinos e ovinos no Semiárido. Petrolina: Embrapa Semiárido, 2011.

FARDO, M.L. A gamificação aplicada em ambientes de aprendizagem. Revista Novas Tecnologias na Educação (RENOTE), v. 11, n. 1, 2013.

FREIRE, N.C.F.; PACHECO, A.P. Uma abordagem geoespacial e espectrotemporal da degradação ambiental no Bioma Caatinga na região de Xingó, Brasil. Ciência \& Trópico, v. 41, n. 2, 2017.

GARDA, A.A.; LION, M.B.; LIMA, S.M. Q.; MESQUITA, D.O.; ARAÚJO, H.F.P.; NAPOLI, M.F. Os animais vertebrados do bioma caatinga. Ciência e Cultura, v. 70, n. 4, p. 29-34. 2018.

GUIMARÃES, M. A dimensão ambiental na educação. Coleção Magistério: Formação e Trabalho Pedagógico. São Paulo: Papirus, 2003. 
ICMBIO - Instituto Chico Mendes de Conservação da Biodiversidade. Livro Vermelho da Fauna Brasileira Ameaçada de Extinção: Volume I. Brasília: ICMBio/MMA, 2018.

IUCN - International Union for Conservation of Nature. IUCN Red List categories and criteria: version 3.1. IUCN Species Survival Commission. 2001.

IUCN, International Union for Conservation of Nature. Guidelines for Application of IUCN Red List Criteria at Regional and National Levels: Version 4.0. IUCN, 2012.

JÖTTEN. M.; CAMARA. A.E. Kapi wara: um jogo de tabuleiro cooperativo ecológico-pedagógico sobre o Rio Pinheiros e suas capivaras. Design \& Tecnologia, v. 13, p. 110-122, 2017.

LEAL, I. R.; TABARELLI, M.; SILVA, J. M. C. Ecologia e conservação da Caatinga. Recife: Editora Universitária UFPE, 2003.

LINHARES, S.; GEWANDSZNAJDER, F. Biologia hoje. São Paulo: Ática, 2010.

MENEZES, I.S.; FREITAS, S.H.S.; CARA, P.A.A.; COUTO-SANTOS, A.P.L. Jogo didático como ferramenta para a Educação Ambiental no município de Itapetininga (BA). Revista Brasileira de Educação Ambiental (RevBEA), v. 11, n. 5, p. 19-29, 2016.

NORMAN, R.S.S.; SEVERIANO, J.S. Educação Ambiental e aves da Caatinga: a construção do conhecimento através de atividades práticas. Revista Brasileira de Educação Ambiental (RevBEA), v. 13, n. 3, p. 42-57, 2018.

PRESTI, F. T.;ALMEIDA, T.A.; SILVA, G.F.; SILVA, H.E.; CONRADO, L.P.; CESPEDE, L.; RODRIGUES, T.M.; BARBIRATO, M.; WASKO, A.P. Conhecendo a arara-azul-grande: confecção e aplicação de um jogo didático como parte das ações de Educação Ambiental visando a conservação da espécie. Revista Brasileira de Educação Ambiental (RevBEA), v. 12, n. 2, p. 259-273, 2017.

ROMANO, C.G.; CARVALHO, A.L.; MATTANO, I.D.; CHAVES, M.R.M.; ANTONIASSI, B. Perfil químico: um jogo para o ensino da tabela periódica. Rev. Virtual Quim., v. 9, n. 3, p. 1235-1244, 2017.

SILVA, J.M.C.; LEAL, I.R.; TABARELLI, M. Caatinga: The Largest Tropical Dry Forest Region in South America. Springer, p. 577. 2017.

TABARELLI, M.; LEAL, I.R.; SCARANO, F.R.; SILVA, J.M.C. Caatinga: legado, trajetória e desafios rumo à sustentabilidade. Ciência e Cultura, v. 70, n. 4, p. 25-29, 2018.

VIVIANI, D.; RODRIGUES, E.A.; EBERT, L. A. O estudo das aves: uma proposta diferenciada para a promoção da educação ambiental. Revista Maiêutica, v. 4, n. 1, p. 115-134, 2016. 